\title{
Peritonitis in children on peritoneal dialysis in Cape Town, South Africa: epidemiology and risks
}

\author{
Renske Raaijmakers • Priya Gajjar • \\ Cornelis Schröder $\cdot$ Peter Nourse
}

Received: 6 January 2010 /Revised: 8 May 2010 / Accepted: 25 May 2010 /Published online: 20 July 2010

(C) The Author(s) 2010. This article is published with open access at Springerlink.com

\begin{abstract}
Peritonitis is a frequent complication of peritoneal dialysis (PD) in children as well in adults. Data on PD and peritonitis in pediatric patients are very scarce in developing countries. A retrospective cohort study was performed between 2000 and 2008 with the aim to evaluate PD treatment and peritonitis epidemiology in pediatric patients in South Africa and identify risk factors for peritonitis. Baseline characteristics and potential risk factors of peritonitis were recorded, including housing, socio-economic circumstances, distance to PD center, type of PD, mode of catheter placement, race, presence of gastrostomy tube, weight, and height. Outcome indices for peritonitis were peritonitis rate, time to first peritonitis, and number of peritonitis-free patients. The patient cohort comprised 67 patients who were on PD for a total of 544 months. The total number of peritonitis episodes was 129 . Median peritonitis rate was one episode every 4.3 patient months (2.8 episodes/patient-year, range 0-21.2). Median time to first infection was 2.03 months (range $0.1-$ 21.5 months), and $28.4 \%$ of patients remained free from peritonitis. Patients with good housing and good socioeconomic circumstances had a significantly lower peritonitis
\end{abstract}

R. Raaijmakers $\cdot$ P. Gajjar $\cdot$ P. Nourse

Department of Pediatric Nephrology,

Red Cross Children's Hospital,

Cape Town, South Africa

R. Raaijmakers $(\bowtie)$

Department of Pediatric Nephrology, 833,

Radboud University Nijmegen Medical Centre,

P.O. Box 9101, 6500 HB Nijmegen, The Netherlands

e-mail: r.raaijmakers@cukz.umcn.nl

e-mail: renskeraaijmakers@gmail.com

C. Schröder

Department of Pediatrics, Gelre Hospital,

Apeldoorn, The Netherlands rate and a longer time to first peritonitis episode. Peritonitis rate was high in this cohort, compared to numbers reported for the developed world; the characteristics of causative organisms are comparable. The most important risk factors for the development of peritonitis were poor housing and poor socioeconomic circumstances. More intensive counseling may be beneficial, but improvement of general socio-economic circumstances will have the greatest influence on PD success.

Keywords Peritonitis · Pediatric · Risk factors

Socio-economic circumstances $\cdot$ Outcome

\section{Introduction}

Frequently occurring diseases in developing countries, such as acquired immunodeficiency syndrome (AIDS), tuberculosis, malaria, gastro-enteritis, and hypertension are often complicated by renal diseases [1]. No reliable statistics are available on causes of end-stage renal disease (ESRD); the only data available are those from dialysis and transplantation, but these databases represent a selection of patients based on eligibility for transplantation as well as those with access to renal replacement therapy. The reported prevalence of patients with ESRD in Africa in 2004 was 70/ million population, and the prevalence of renal replacement therapy (RRT) was 65/million population. The global prevalence in 2004 for ESRD was 280/million population, with a prevalence of RRT of $215 /$ million population [2]. These numbers clearly reflect an under-reporting of ESRD in Africa together with a shortage of renal replacement therapy. In recent years, peritoneal dialysis (PD) has become increasingly available in developing countries. PD has been described as the dialysis technique of choice in developing countries, where mass poverty and poor 
resources play an important role in health care [3]. PD can be performed at a relatively low cost as it is less reliant than other dialysis techniques on expensive infrastructure and health professionals. Also, because it is a homebased technique, there are savings on travel expenses. In developing countries, PD is becoming increasingly available as a renal replacement modality. In 2004, the worldwide growth was $11 \%$ in countries other than Europe, the USA or Japan, where no growth was observed [2]. In developing countries, dialysis patients tend to be of a younger age than in developed countries [2].

The first reported experiences with PD in South Africa originate from the 1980s $[4,5]$. These early attempts were successful, but multiple problems were encountered which restricted the success rate. The most important of these were a lack of transportation, poor housing and sanitation, inadequate education, and poor acceptance of therapy.

Peritonitis is a frequent complication of PD in both children and adults. Peritonitis characteristics in children vary highly over the world, influenced by geographical and socio-economic differences, among other factors [6].

Data on PD and peritonitis in pediatric patients in developing countries are scarce. In the study reported here, we evaluated the epidemiology of peritonitis in children on PD in Cape Town, South Africa and identified potential risk factors for peritonitis.

\section{Materials and Methods}

\section{Ethics}

The study was approved by the hospital ethics committee.

\section{Study design}

A retrospective clinical cohort study was carried out at the Red Cross Children's Hospital in Cape Town, South Africa. The Red Cross Children's Hospital is one of two university hospitals in South Africa where pediatric PD is performed. Only patients considered to be eligible for transplantation are accepted into the dialysis program. Data on all patients aged from 0 to 18 years enrolled in the PD program between 2000 and 2008 were analyzed.

\section{Patients}

The patient cohort comprised 67 patients (35 males, 32 females) who were treated with PD for a total of 544 months. Median age at the start of the PD treatment was 10.1 years (range 1.2-17.4 years). The age distribution of the patients is given in Fig. 1. Median time on PD was 7.0 months (range $0.4-36.8$ months). All patients were on
PD due to ESRD. Underlying diseases were glomerulonephritis $(24 \%)$, dysplastic kidneys (16\%), focal segmental glomerulosclerosis (13\%), reflux nephropathy $(9 \%)$, nephrotic syndrome $(5 \%)$, urethral valves $(5 \%)$, hemolytic uremic syndrome (3\%), unknown (12\%), and other diseases (13\%; nephronopthisis, primary hyperoxaluria, cystinosis, Alport, systemic lupus erythematosus, infection). All patients in this cohort had single-cuff, upward-pointing, straight catheters for dialysis, as this type of catheter is preferred by the local surgeons due to it being easier to remove if necessary. The same type of catheter was used in all patients to achieve maximum routine and, hence, a smaller risk of operation-related complications. Omentectomy was performed as a routine where possible. When not in use (2-week periods), catheters were secured to the abdomen and not redressed during this time. Antibiotics were not routinely given at time of placement.

Training on exit-site care was provided standard for all patients. Nurses teach patients and parents about exit-site care, including dressing and general hygiene. All peritonitis episodes were primarily treated according to the local protocol with cefotaxime and vancomycin intraperitoneally. Treatment was individualized once culture results were available.

\section{Methods}

Demographic and biomedical data were obtained by evaluating the patients' medical records. Socio-economic data were clinically evaluated by a clinical social worker and the pediatric nephrologist taking care of the patient. Patient baseline characteristics, patient survival, technique survival, and all episodes of peritonitis were analyzed. For each peritonitis episode, the causative organism, occurrence of a Gram-negative or fungal infection (noted as severe infection because of the relative high risk of catheter removal, technique failure, and relapse [7-9]), occurrence of technique failure because of peritonitis, and survival after peritonitis were recorded.

The following primary peritonitis outcome indices were assessed: (1) peritonitis rate (expressed as one peritonitis episode every $x$ patient-month and as number of episodes/patient-year); (2) peritonitis-free period (time to first peritonitis episode); (3) peritonitis-free patients [patients not suffering from peritonitis vs. all patients that suffered from one or more peritonitis episodes and vs. the $25 \%$ of the patients with the highest rate of peritonitis (rate $>0.4$ /patient month)]. The occurrence of peritonitis was diagnosed by a pediatric nephrologist. Patients were considered to have peritonitis when two of the following criteria were present: abdominal pain, cloudy dialysis fluid, leukocyte count $>100 / \mathrm{mm}^{3}$, and/or positive culture of dialysis fluid. An infection with the same causative organism as that in the immediately preceding episode 
Fig. 1 Age distribution of patients enrolled in the study

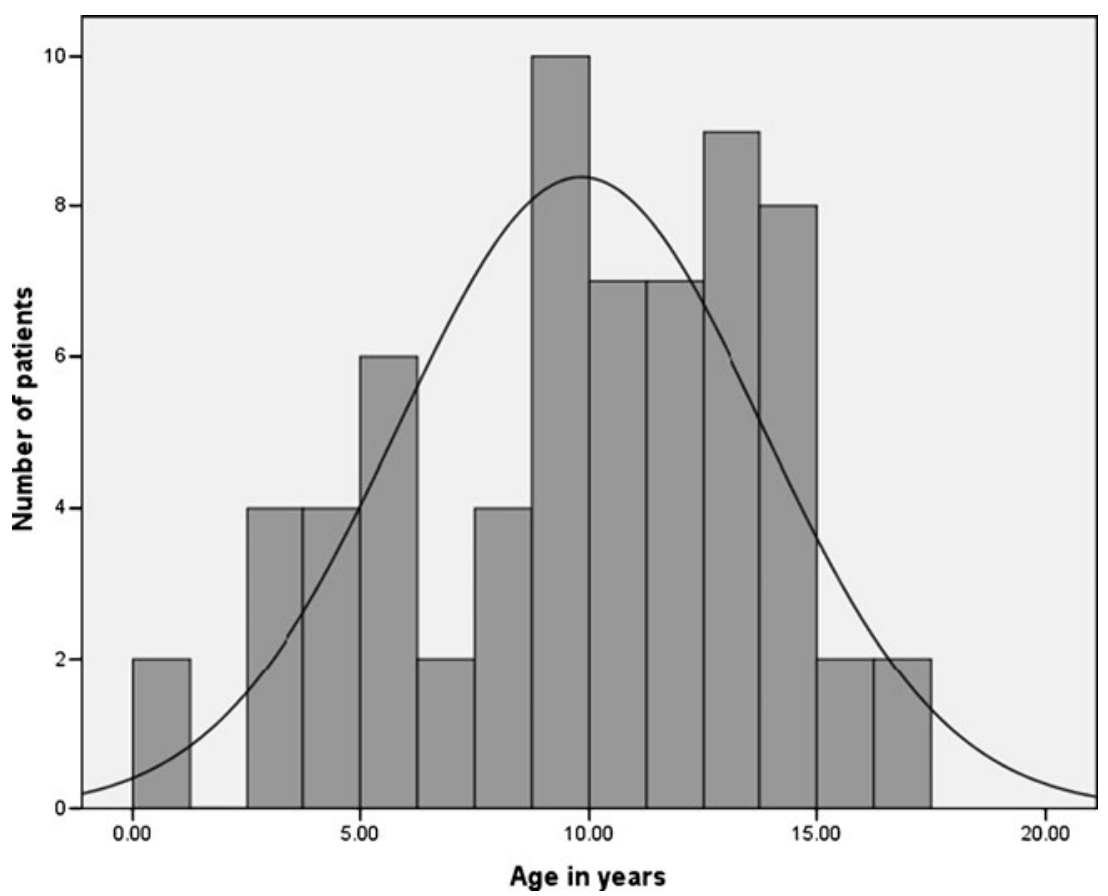

(based on culture results and antibiotic susceptibilities) within 4 weeks after completion of the first antibiotic treatment was considered as a recurrent peritonitis and was not included in our data as a new peritonitis episode. Possible risk factors were assessed in all patients: age of the patient (in months); weight and height (both expressed as: good $>10$ th percentile; fair 3 rd to 10 th percentile; poor $<3$ rd percentile); type of PD [continuous ambulatory PD (CAPD) vs. nightly intermittent PD (NIPD)]; mode of catheter placement (laparoscopic vs. laparotomic); distance to PD center (more or less than $200 \mathrm{~km}$ ); presence of gastrostomy tube; race (black vs. black mixed with other races vs. white); housing; socio-economic circumstances. The assessment of housing was based on three criteria, namely, the availability of electricity, running water, and adequate sanitation with bathroom facilities, respectively. Housing was classified as good when electricity, running water, and bathroom facilities were all available, as fair when any one of these three criteria was missing, and as poor when two or more of these three criteria were missing. Institutional housing (in hospital or clinical care center) was classified as a separate category. Criteria for the assessment of socio-economic circumstances were: (1) one or two parents/care-givers present; (2) employment of care-givers; (3) availability of adequate social support in and around the family. Socio-economic circumstances were classified as good when two parents/care-givers were present, one or both care-givers were employed, and an adequate social network was in place. They were classified as fair when any one of the above three criteria was suboptimal (e.g. only one care-giver present or unemployment of care-givers or inadequate social network) and as poor when two or more of the above three criteria were suboptimal.

\section{Statistical analysis}

Variables were not distributed normally, therefore results were expressed as medians, ranges, and percentages, and outcome indices were assessed with non-parametric tests and with different types of tests to improve the robustness of the statistical analysis. Spearman's correlation coefficient was calculated for the continuous risk factor, age. Differences between categorical dichotomous risk factors (type of PD, catheter placement, and distance to PD center) were tested with the Mann-Whitney $U$ test. For categorical risk factors with more than two categories (for the risk factors weight, height, housing and socio-economic circumstances), both the Kruskal-Wallis test as well as the Mann-Whitney $U$ test were performed, whereby with the Mann-Whitney $U$ test the category 'good' was tested against the other categories. For the risk factor 'race', black, mixed, and white race were tested separately with the Kruskal-Wallis test as well as combined (black/mixed vs. white) with the Mann Whitney- $U$ test. For the outcome variable 'time to first peritonitis', peritonitis episodes without an exact time indication and peritonitis-free patients were excluded. The outcome variable 'peritonitis-free patients' was tested dichotomously with chi-square tests. For statistically significant risk factors, the degree of correlation was tested with linear backward regression with multicollinearity diagnostics. Collinearity diagnostics give an estimation of the independent effect of specific risk factors, 
and the degree of collinearity is a measure for the correlation between risk factors. Kaplan-Meier hazard regression analysis was used for the cumulative risk of developing a first infection, according to Vonesh et al. [10]. This analysis compared the relative probability of developing a first infection between subgroups of the study population. Differences were considered significant at $p$ values $<0.05$.

\section{Results}

During the total treatment period of 544 months, 129 peritonitis episodes occurred. The median peritonitis rate was one episode every 4.3 patient-months, or 2.8 episodes per patient-year (range 0-21.2). The distribution of the peritonitis rate over the total patient group is shown in Fig. 2. Median time from initiation of PD to first peritonitis was 2.03 months (range 0.1-21.5 months). Eleven patients experienced their first peritonitis episode within the first month on PD, and 19 patients (28.4\%) remained free from peritonitis. Median time on dialysis was 7.0 months. Classification of the peritonitis episodes according to causative organism is shown in Table 1 . In $10 \%$ of the cultures, the causative organism remained unclassified and could not be identified in the respective patients. Eleven patients developed a fungal peritonitis $(14.9 \%$ of all patients, $7.7 \%$ of all peritonitis episodes). Of these patients, $91 \%$ had suffered from one or more bacterial peritonitis episodes prior to the fungal peritonitis episode. The fungal peritonitis patients also experienced a significantly higher number of peritonitis episodes $(p=0.001)$, a significantly higher peritonitis incidence $(p=0.006)$, and a higher rate of technique failure $(p=0.0001)$ compared to the other patients. One patient developed a tuberculous peritonitis, with good clinical outcome. Patient survival on peritoneal dialysis was $100 \%$. Technique failure with a temporary switch to hemodialysis occurred in 11 patients $(16.4 \%)$ and was significantly higher in patients with a higher peritonitis rate $(p=0.001)$. Fifty-three patients $(79.1 \%)$ were transplanted.

All potential risk factors for the peritonitis indices were analyzed. No correlation was found between age and peritonitis incidence (Spearman's correlation coefficient $-0.009, p=0.94$ ) or between age and peritonitis-free period (Spearman's correlation coefficient $0.14, p=0.42$ ). Our analysis of all dichotomous risk factors is shown in Tables 2 and 3. With good housing, peritonitis incidence was significantly lower $(p=0.03)$ and the peritonitis-free period longer, nearly reaching significance $(p=0.052)$, compared to fair and poor housing. When all types of housing were tested separately by the Kruskal-Wallis test, small numbers of patients were present in each subgroup, and these results did not reach significance (data not shown). When good socio-economic circumstances were compared to fair and poor socio-economic circumstances, the peritonitis rate was significantly lower $(p=0.02)$ and time to first peritonitis was longer $(p 2=0.01)$. These results remained statistically significant when all three socio-economic categories were tested separately with the Kruskal-Wallis test, despite relatively small numbers in each subgroup, with $p$ values of 0.006 and 0.03 for peritonitis incidence and time to first peritonitis, respectively (Table 4).

The statistically significant risk factors housing and socio-economic circumstances were positively correlated, but collinearity was sufficiently low (variance inflation factor 1.28 , tolerance 0.78 ), so the degree of correlation was not considered to be a bias factor in the analysis.

Peritonitis-free patients had significantly better housing and social circumstances than patients with the highest rate of peritonitis.

The cumulative hazard for having a first peritonitis was evaluated for 53 patients (excluding the patients for whom the exact time of the first peritonitis episode was unknown). Patients with good socio-economic circumstances had a significantly lower cumulative hazard than those with fair and poor socio-economic circumstances ( $p=0.003$ ) (Fig. 3). Patients with good housing also had a lower cumulative hazard for developing a first peritonitis compared to fair and poor housing ( $p=0.001)$ (Fig. 4). For the combined risk factors housing and socio-economic circumstances, the same trend was seen, but it was even more pronounced $(p<0.0001)$ (Fig. 5).

\section{Discussion}

In this study, an overview of peritoneal dialysis and peritonitis in pediatric patients in Cape Town, South Africa is given, the epidemiology of peritonitis is evaluated, and risk factors are identified. Among our patients, socio-economic circumstances and quality of housing significantly influenced the peritonitis rate, and socio-economic circumstances also significantly influenced time to first peritonitis episode. When both socioeconomic circumstances and housing were fair or poor, the cumulative risk to develop peritonitis was even more elevated than that for the separate categories alone. The higher risk group for housing includes the subgroup 'institutional housing'. The poor results in this group were most likely due suboptimal PD care due to nursing staff shortages, especially in the clinical care center where children were not well supervised or supervised by inexperienced staff. Children only go to this clinical care center when the situation at home is considered too unfavorable to perform dialysis, so this may reflect a pre-selection bias in this subgroup. Socio-economic risk factors have been investigated in only a few adult PD 
Fig. 2 Peritonitis rate distribution of all patients

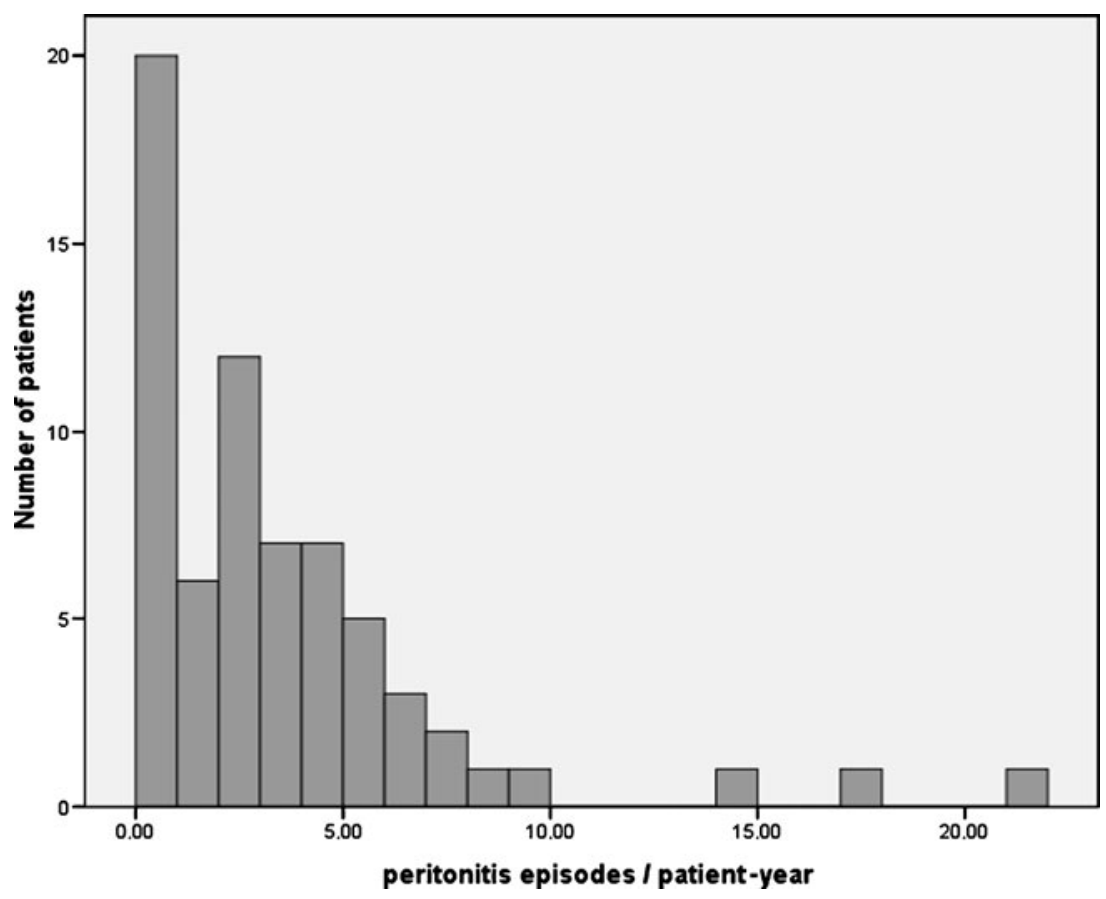

studies [3, 11]. In a South African study by Zent et al. [11], poor socio-economic status (SES) and inadequate housing (high occupants-to-bedroom ratio, no electricity), alcohol abuse, and psychiatric disease were found to be associated with higher peritonitis rates. Black race was also associated with higher peritonitis rates in the study by Zent, but this reflected merely the poorer socioeconomic conditions of this population group. In our study, the large majority of our patients were black or black mixed with other races, and no influence of race on peritonitis rate was found. In another South African study, Katz et al. [3] were unable to confirm a relationship between socio-economic parameters and peritonitis rate: education, employment status, home conditions, and earnings did not influence peritonitis and technique failure in their study. Two pediatric studies have also examined socio-economic risk factors in PD. The study by Grunberg et al. [12], performed in Uruguay, showed no differences in patient and technique survival due to
SES, while Ariza et al. [13] reported a higher peritonitis rate for Venezuelan pediatric patients with lower SES.

Socio-economic circumstances can be assessed in many ways, and it is a challenge to obtain an objective and adequate mode of measurement that neither loses clarity because of too many details nor loses important information by fitting data into a simplified model. The above-mentioned studies all used an equivalent of the same criteria that we used in our study, with classifications based on education/employment, housing, social support, and family income. Grunberg et al. and Ariza et al. used a modification of an old scoring system, called the 'Graffar' score [14], which divides SES into categories based on parents' education, parents' educational level, and family source of income. A possible flaw in our study is the absence of a criterion on family income, but inadequate data were available to include this in our classification of socioeconomic circumstances.

For the other potential risk factors that were analyzed in this study, we did not find a statistical relationship with peritonitis
Table 1 Classification of causative organisms

\footnotetext{
${ }^{a}$ A fungus and a Gram-negative organism were both cultured in one culture
}

\begin{tabular}{lll}
\hline Causative agents & Number of peritonitis episodes & Percentage \\
\hline Gram-positive & 39 & 30.2 \\
Gram-negative & $29(+1)^{\mathrm{a}}$ & 23.3 \\
Fungal & $9(+1)^{\mathrm{a}}$ & 7.7 \\
Mycobacterium tuberculosis & 1 & 0.8 \\
Fungal and Gram-negative & $1^{\mathrm{a}}$ & 0.8 \\
Culture-negative & 37 & 28.7 \\
Unknown & 13 & 10.1 \\
Total & 129 & 100 \\
\hline
\end{tabular}


Table 2 Mann-Whitney $U$ test for potential risk factors

\begin{tabular}{|c|c|c|c|c|c|c|}
\hline \multirow[t]{2}{*}{ Potential risk factors } & \multicolumn{3}{|c|}{$\begin{array}{l}\text { Peritonitis rate: peritonitis/patient- } \\
\text { year }\end{array}$} & \multicolumn{3}{|c|}{$\begin{array}{l}\text { Peritonitis-free period: time to first peritonitis episode } \\
\text { (months) }\end{array}$} \\
\hline & Median & Range & $p$ & Median & Range & $p$ \\
\hline $\begin{array}{l}\text { Distance to PD center }>200 \mathrm{~km} \\
\text { Distance to PD center }<200 \mathrm{~km}\end{array}$ & $\begin{array}{l}2.81 \\
2.49\end{array}$ & $\begin{array}{l}0-21.2 \\
0-9.2\end{array}$ & 0.39 & $\begin{array}{l}2.7 \\
1.8\end{array}$ & $\begin{array}{l}0.33-21.5 \\
0-8.9\end{array}$ & 0.15 \\
\hline $\begin{array}{l}\text { Type of PD: NIPD } \\
\text { Type of PD: CAPD }\end{array}$ & $\begin{array}{l}2.83 \\
1.99\end{array}$ & $\begin{array}{l}0-17.6 \\
0-7.45\end{array}$ & 0.75 & $\begin{array}{l}2.2 \\
1.8\end{array}$ & $\begin{array}{l}0.07-21.5 \\
0-5.73\end{array}$ & 0.18 \\
\hline $\begin{array}{l}\text { Catheter placement laparoscopic } \\
\text { Catheter placement open }\end{array}$ & $\begin{array}{l}2.94 \\
2.69\end{array}$ & $\begin{array}{l}0-21.2 \\
0-9.20\end{array}$ & 0.36 & $\begin{array}{l}2.2 \\
1.8\end{array}$ & $\begin{array}{l}0-8.9 \\
0.87-2.8\end{array}$ & 0.73 \\
\hline $\begin{array}{l}\text { Weight good } \\
\text { Weight fair/poor }\end{array}$ & $\begin{array}{l}2.02 \\
2.86\end{array}$ & $\begin{array}{l}0-17.6 \\
0-21.2\end{array}$ & 0.47 & $\begin{array}{l}1.8 \\
2.2\end{array}$ & $\begin{array}{l}0.43-2.83 \\
0-21.5\end{array}$ & 0.21 \\
\hline $\begin{array}{l}\text { Height good } \\
\text { Height fair/poor }\end{array}$ & $\begin{array}{l}2.56 \\
2.76\end{array}$ & $\begin{array}{l}0-17.6 \\
0-21.2\end{array}$ & 0.51 & $\begin{array}{l}1.23 \\
2.03\end{array}$ & $\begin{array}{l}0.43-2.83 \\
0-21.5\end{array}$ & 0.60 \\
\hline $\begin{array}{l}\text { Housing good } \\
\text { Housing fair/poor/ institutional }\end{array}$ & $\begin{array}{l}2.21 \\
3.86\end{array}$ & $\begin{array}{l}0-7.56 \\
0-21.2\end{array}$ & 0.03 & $\begin{array}{l}2.52 \\
1.37\end{array}$ & $\begin{array}{l}0.37-21.5 \\
0-8.87\end{array}$ & 0.052 \\
\hline $\begin{array}{l}\text { Socio-economic circumstances good } \\
\text { Socio-economic circumstances fair/poor }\end{array}$ & $\begin{array}{l}1.91 \\
3.88\end{array}$ & $\begin{array}{l}0-17.6 \\
0-21.2\end{array}$ & 0.02 & $\begin{array}{l}2.83 \\
1.35\end{array}$ & $\begin{array}{l}0.43-21.5 \\
0-8.87\end{array}$ & 0.01 \\
\hline $\begin{array}{l}\text { Race black/mixed } \\
\text { Race white }\end{array}$ & $\begin{array}{l}2.81 \\
1.13\end{array}$ & $\begin{array}{l}0-21.2 \\
0-5.71\end{array}$ & 0.27 & $\begin{array}{l}1.8 \\
6.97\end{array}$ & $\begin{array}{l}0.1-8.87 \\
2.83-21.47\end{array}$ & 0.085 \\
\hline $\begin{array}{l}\text { Gastrostomy tube no } \\
\text { Gastrostomy tube yes }\end{array}$ & $\begin{array}{l}2.69 \\
4.46\end{array}$ & $\begin{array}{l}0-21.2 \\
2-5.71\end{array}$ & 0.45 & $\begin{array}{l}2.07 \\
1.8\end{array}$ & $\begin{array}{l}0-21.47 \\
0.5-6.97\end{array}$ & 0.97 \\
\hline
\end{tabular}

PD, Peritoneal dialysis; NIPD, nightly intermittent peritoneal dialysis; CAPD, continuous ambulatory peritoneal dialysis

outcome indices. Distance to the PD center did not influence peritonitis rates in our study, neither did it in the study of Grunberg et al. [12]. Younger age has been identified as a possible risk factor for adults as well as children [11, 15-17], but this association was not found in our study. In our patients, no relationship was found between catheter insertion technique or type of PD and peritonitis outcome. In a large systematic review of randomized controlled trials by Strippoli et al. [18], statistically significant differences in peritonitis rates with catheter type or

Table 3 Chi-square test for potential risk factors: peritonitis-free patients versus all patients with peritonitis and peritonitis-free patients versus patients with the highest rate of peritonitis

\begin{tabular}{|c|c|c|c|c|c|c|}
\hline \multirow[t]{2}{*}{ Risk factors } & \multicolumn{3}{|c|}{ Peritonitis Yes vs. No peritonitis } & \multicolumn{3}{|c|}{ Peritonitis High rate vs. No peritonitis } \\
\hline & Yes & No & $p$ & High rate & No & $p$ \\
\hline $\begin{array}{l}\text { Distance to PD center }>200 \mathrm{~km} \\
\text { Distance to PD center }<200 \mathrm{~km}\end{array}$ & $\begin{array}{l}28 \\
20\end{array}$ & $\begin{array}{l}9 \\
10\end{array}$ & 0.42 & $\begin{array}{l}12 \\
4\end{array}$ & $\begin{array}{l}9 \\
10\end{array}$ & 0.10 \\
\hline $\begin{array}{l}\text { Type of PD: NIPD } \\
\text { Type of PD: CAPD }\end{array}$ & $\begin{array}{l}32 \\
13\end{array}$ & $\begin{array}{l}9 \\
8\end{array}$ & 0.18 & $\begin{array}{l}11 \\
3\end{array}$ & $\begin{array}{l}9 \\
8\end{array}$ & 0.14 \\
\hline $\begin{array}{l}\text { Catheter placement laparoscopic } \\
\text { Catheter placement open }\end{array}$ & $\begin{array}{l}18 \\
10\end{array}$ & $\begin{array}{l}6 \\
5\end{array}$ & 0.57 & $\begin{array}{l}7 \\
4\end{array}$ & $\begin{array}{l}6 \\
5\end{array}$ & 0.67 \\
\hline $\begin{array}{l}\text { Weight good } \\
\text { Weight fair/poor }\end{array}$ & $\begin{array}{l}11 \\
37\end{array}$ & $\begin{array}{l}8 \\
11\end{array}$ & 0.12 & $\begin{array}{l}5 \\
11\end{array}$ & $\begin{array}{l}8 \\
11\end{array}$ & 0.51 \\
\hline $\begin{array}{l}\text { Height good } \\
\text { Height fair/poor }\end{array}$ & $\begin{array}{l}9 \\
39\end{array}$ & $\begin{array}{l}7 \\
12\end{array}$ & 0.12 & $\begin{array}{l}4 \\
12\end{array}$ & $\begin{array}{l}7 \\
12\end{array}$ & 0.45 \\
\hline $\begin{array}{l}\text { Housing good } \\
\text { Housing fair/poor/institutional }\end{array}$ & $\begin{array}{l}24 \\
24\end{array}$ & $\begin{array}{l}14 \\
4\end{array}$ & 0.08 & $\begin{array}{l}5 \\
11\end{array}$ & $\begin{array}{l}14 \\
4\end{array}$ & 0.01 \\
\hline $\begin{array}{l}\text { Socio-economic circumstances good } \\
\text { Socio-economic circumstances fair/poor }\end{array}$ & $\begin{array}{l}21 \\
27\end{array}$ & $\begin{array}{l}13 \\
6\end{array}$ & 0.07 & $\begin{array}{l}5 \\
11\end{array}$ & $\begin{array}{l}13 \\
6\end{array}$ & 0.03 \\
\hline $\begin{array}{l}\text { Race black/mixed } \\
\text { Race white }\end{array}$ & $\begin{array}{l}45 \\
3\end{array}$ & $\begin{array}{l}16 \\
2\end{array}$ & 0.51 & $\begin{array}{l}11 \\
1\end{array}$ & $\begin{array}{l}16 \\
2\end{array}$ & 0.8 \\
\hline $\begin{array}{l}\text { Gastrostomy no } \\
\text { Gastrostomy yes }\end{array}$ & $\begin{array}{l}43 \\
5\end{array}$ & $\begin{array}{l}18 \\
1\end{array}$ & 0.67 & $\begin{array}{l}14 \\
2\end{array}$ & $\begin{array}{l}18 \\
1\end{array}$ & 0.45 \\
\hline
\end{tabular}


Table 4 Kruskal-Wallis test for socio-economic circumstances

Socio-economic circumstances Peritonitis rate: peritonitis/patient year

Peritonitis-free period: time to first peritonitis episode

\begin{tabular}{|c|c|c|c|c|c|c|}
\hline & & \\
\hline & Median (number of patients) & Range & $p$ & Median (number of patients) & Range & $p$ \\
\hline Socio-economic circumstances good & $1.91(34)$ & $0-17.6$ & 0.006 & $2.83(14)$ & $0.43-21.5$ & 0.03 \\
\hline Socio-economic circumstances fair & $2.94(22)$ & $0-9.20$ & & $1.80(11)$ & $0.10-8.87$ & \\
\hline Socio-economic circumstances poor & $4.86(11)$ & $1.99-21.2$ & & $0.87(9)$ & $0.10-2.77$ & \\
\hline
\end{tabular}

catheter insertion technique were also not found. A possible bias in the epidemiology of our PD population is the fact that only patients eligible for transplantation were included in the dialysis program, influencing, in particular, the time on PD, which was relatively short in our study due to a high transplantation rate.

Peritonitis rates in general were high in our patient group, namely, 2.8 episodes/patient-year, compared to those reported in other pediatric studies. This is especially true if we compare our rate to those reported in studies from developed countries, such as Japan, with 0.29 episodes/patient-year [19], the USA, with 0.19-0.91 episodes/patient-year [16, 20], and Europe, with 0.71-1.1 episodes/patient-year [7, 15, 17]. Compared to studies from South America, where 1.3-2.1 episodes/patientyear have been reported $[12,13]$, our peritonitis rates are also still relatively high. Worse socio-economic circumstances in developing countries with poor hygiene provide a clear explanation for these differences. Cultural factors also probably play a role when one region is compared to another. The pattern of causative organisms in other studies comprised 44-64\% Gram-positive infections, 14-25\% Gram-negative infections, 2-7\% fungal infections, and 14 $31 \%$ cultures remaining negative $[7,16,19,21]$. These percentages are rather comparable to those in our study. The rather low percentage of Gram-positive infections, however, is probably an underestimation due to the relative high percentage of culture-negative peritonitis episodes and the percentage of unknown cultures (10\%). The percentage of peritonitis episodes due to unknown organisms and that of the culture-negative peritonitis episodes adds up to $39 \%$, indicating that the percentage of peritonitis episodes for which no specific information about a causative organism was available is particularly high in our study. The fact that in all these cases only empiric treatment was given may help to explain the high incidence of fungal peritonitis. Another explanation for the high percentage of fungal peritonitis is the overall high peritonitis rate and the relative high rate of Gram-negative infections, both of which can be considered
Fig. 3 Kaplan-Meier hazard model for socio-economic circumstances

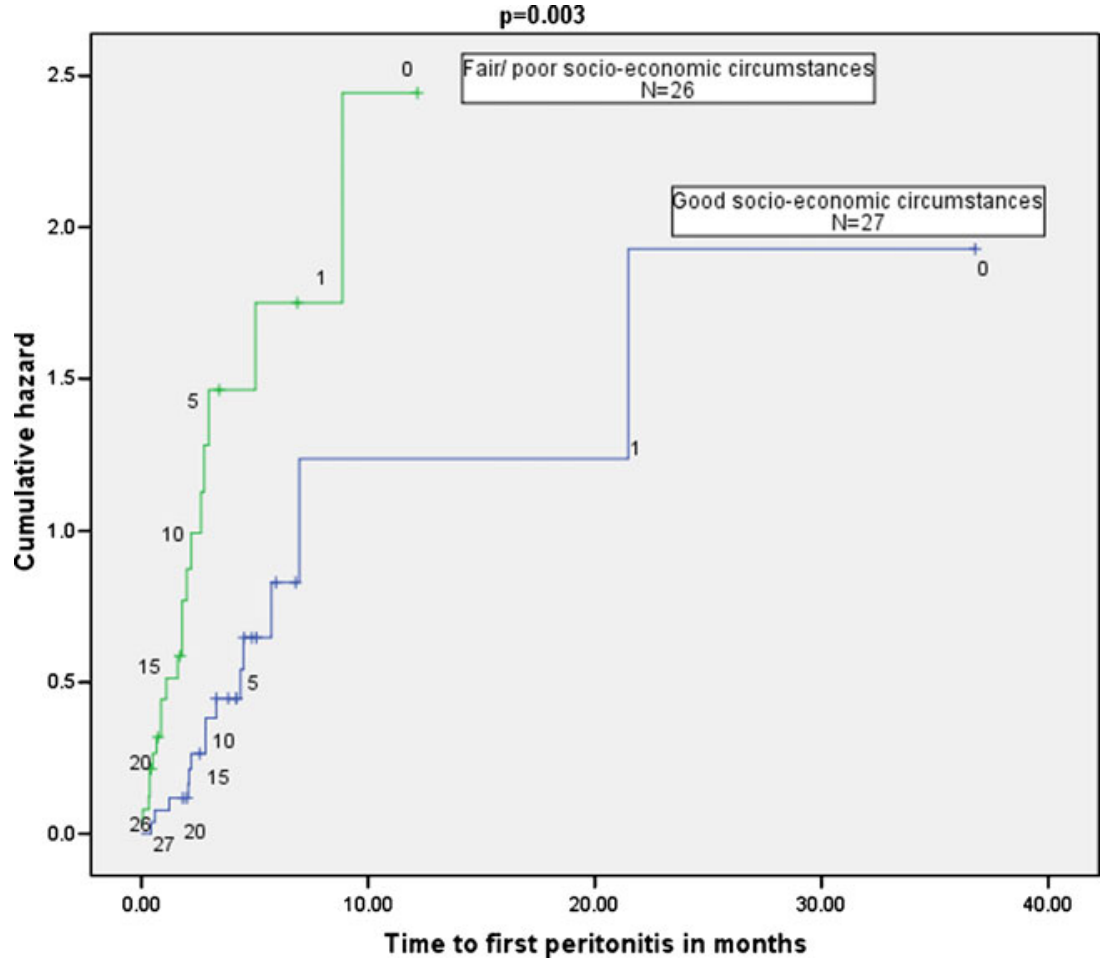


Fig. 4 Kaplan-Meier hazard model for housing $\mathrm{p}=\mathbf{0 . 0 0 1}$

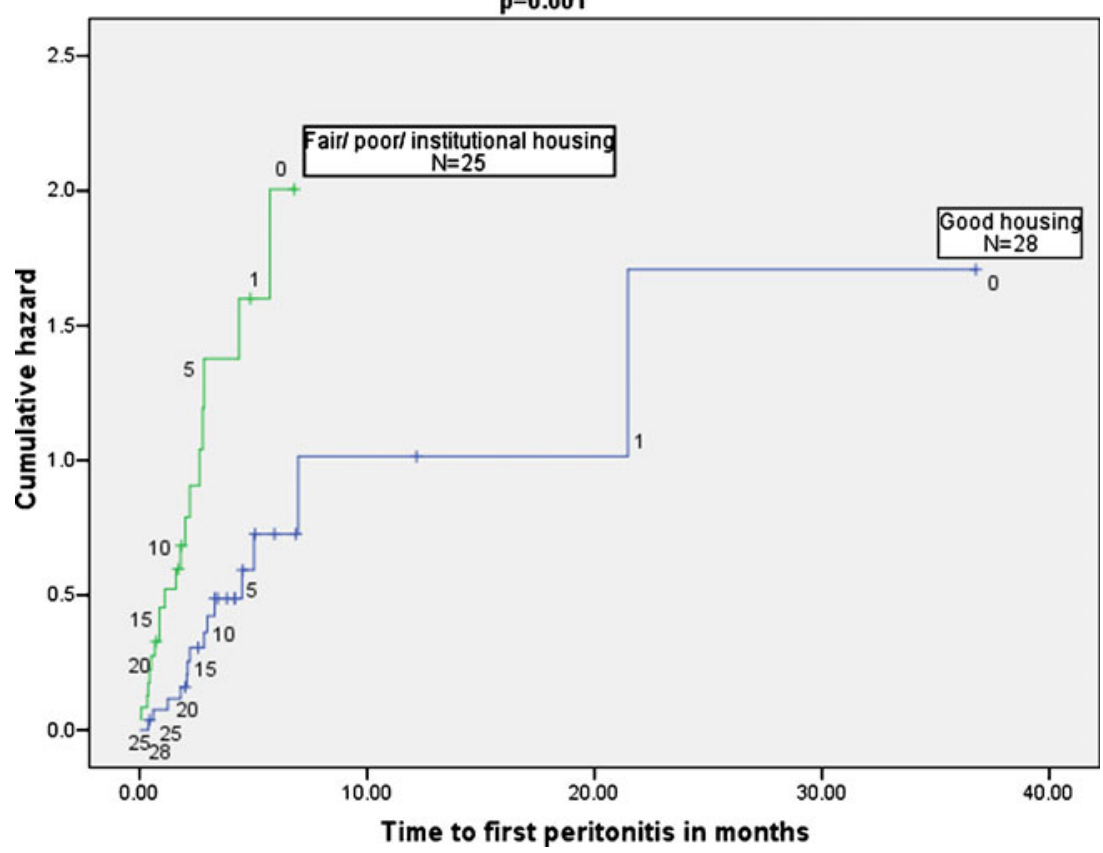

to be a risk factor for fungal peritonitis $[7,8]$. One patient in this study was diagnosed with peritonitis caused by Mycobacterium tuberculosis. Mycobacterium infections rates are increasing worldwide, and dialysis patients are at higher risk of acquiring mycobacterial infections due to impaired cellular immunity associated with chronic renal failure [22]. Only two cases of tuberculous peritonitis in children on PD have been reported prior to our study [23]. Since tuberculous peritonitis is difficult to diagnose, the actual rates could very well be higher than reported. A more extensive evaluation of culture-negative peritonitis and peritonitis resistant to antibiotic treatment could reveal more cases.

In conclusion, PD is an important modality for renal replacement therapy, especially in developing countries, where the use of PD has been expanding in recent years. Poor socio-economic circumstances play an important role in these societies and influence the peritonitis rate and the success rate of PD. More intensive social counseling and
Fig. 5 Kaplan-Meier hazard model for socio-economic circumstances and housing combined

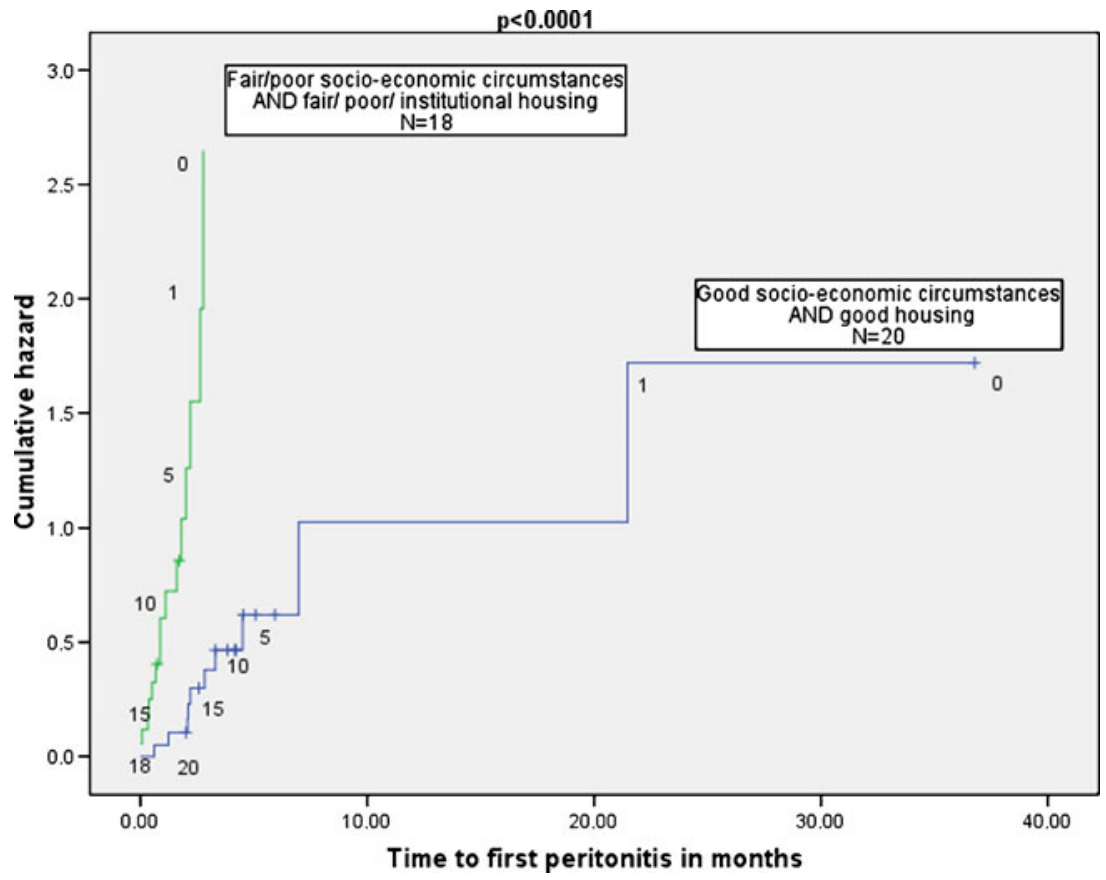


education can hopefully decrease infection rates and rates of PD failure, but an improvement in general socioeconomic circumstances will be the factor with the greatest influence on PD success.

Open Access This article is distributed under the terms of the Creative Commons Attribution Noncommercial License which permits any noncommercial use, distribution, and reproduction in any medium, provided the original author(s) and source are credited.

\section{References}

1. Naicker S (2003) End-stage renal disease in sub-Saharan and South Africa. Kidney Int Suppl 83:S119-S122

2. Grassmann A, Gioberge S, Moeller S, Brown G (2005) ESRD patients in 2004: global overview of patient numbers, treatment modalities and associated trends. Nephrol Dial Transplant 20:2587-2593

3. Katz IJ, Sofianou L, Hopley M (2001) An African communitybased chronic ambulatory peritoneal dialysis programme. Nephrol Dial Transplant 16:2395-2400

4. Di Bisceglie AM, Mzamane DV (1983) Continuous peritoneal dialysis in a developing population-problems seen at Baragwanath Hospital. S Afr Med J 63:405-406

5. Seedat YK (1984) Continuous ambulatory peritoneal dialysis in South Africa. S Afr Med J 65:229-230

6. Schaefer F, Feneberg R, Aksu N, Donmez O, Sadikoglu B, Alexander SR, Mir S, Ha IS, Fischbach M, Simkova E, Watson AR, Moller K, von Baum H, Warady BA (2007) Worldwide variation of dialysis-associated peritonitis in children. Kidney Int 72:1374-1379

7. Raaijmakers R, Schroder C, Monnens L, Cornelissen E, Warris A (2007) Fungal peritonitis in children on peritoneal dialysis. Pediatr Nephrol 22:288-293

8. Warady BA, Bashir M, Donaldson LA (2000) Fungal peritonitis in children receiving peritoneal dialysis: A report of the NAPRTCS. Kidney Int 58:384-389

9. Zurowska A, Feneberg R, Warady BA, Zimmering M, Monteverde M, Testa S, Calyskan S, Drozdz D, Salusky I, Kemper MJ, Ekim M, Verrina E, Misselwitz J, Schaefer F (2008) Gram-negative peritonitis in children undergoing long-term peritoneal dialysis. Am J Kidney Dis $51: 455-462$
10. Vonesh EF (1991) Which statistical method to use when analyzing the incidence of peritoneal dialysis related infections? Perit Dial Int 11:301-304

11. Zent R, Myers JE, Donald D, Rayner BL (1994) Continuous ambulatory peritoneal dialysis: an option in the developing world? Perit Dial Int 14:48-51

12. Grunberg J, Verocay MC, Rebori A, Ramela V, Amaral C, Hekimian G, Viera M, Pouso J (2005) Twenty years' pediatric chronic peritoneal dialysis in Uruguay: patient and technique survival. Pediatr Nephrol 20:1315-1319

13. Ariza M, Lopez M, Quesada T (1991) Complications of CAPD in children: six years experience in Caracas, Venezuela. Adv Perit Dial 7:269-271

14. Graffar M (1956) Une methode de classification sociale d'echantillons de population. Courrier 332:133-138

15. Boehm M, Vecsei A, Aufricht C, Mueller T, Csaicsich D, Arbeiter K (2005) Risk factors for peritonitis in pediatric peritoneal dialysis: a single-center study. Pediatr Nephrol 20:1478-1483

16. Furth SL, Donaldson LA, Sullivan EK, Watkins SL (2000) Peritoneal dialysis catheter infections and peritonitis in children: a report of the North American Pediatric Renal Transplant Cooperative Study. Pediatr Nephrol 15:179-182

17. Schaefer F, Klaus G, Muller-Wiefel DE, Mehls O (1999) Current practice of peritoneal dialysis in children: results of a longitudinal survey. Mid European Pediatric Peritoneal Dialysis Study Group (MEPPS). Perit Dial Int 19[Suppl 2]:S445-S449

18. Strippoli GF, Tong A, Johnson D, Schena FP, Craig JC (2004) Antimicrobial agents to prevent peritonitis in peritoneal dialysis: a systematic review of randomized controlled trials. Am J Kidney Dis 44:591-603

19. Hoshii S, Wada N, Honda M (2006) A survey of peritonitis and exit-site and/or tunnel infections in Japanese children on PD. Pediatr Nephrol 21:828-834

20. Auron A, Simon S, Andrews W, Jones L, Johnson S, Musharaf G, Warady BA (2007) Prevention of peritonitis in children receiving peritoneal dialysis. Pediatr Nephrol 22:578-585

21. Warady BA, Feneberg R, Verrina E, Flynn JT, Muller-Wiefel DE, Besbas N, Zurowska A, Aksu N, Fischbach M, Sojo E, Donmez O, Sever L, Sirin A, Alexander SR, Schaefer F (2007) Peritonitis in children who receive long-term peritoneal dialysis: a prospective evaluation of therapeutic guidelines. J Am Soc Nephrol 18:2172-2179

22. Akpolat T (2009) Tuberculous peritonitis. Perit Dial Int 29[Suppl 2]: S166-S169

23. Ferrara E, Lemire J, Grimm PC, Reznik VM, Mendoza SA, Leake JA, Benador NM (2004) Mycobacterial peritonitis in pediatric peritoneal dialysis patients. Pediatr Nephrol 19:114-117 